\title{
An Experimental Approach of a Driven Pile in Transparent Soils
}

\author{
Laura Ibagón ${ }^{1,2}$, Bernardo Caicedo ${ }^{1}$ \\ ${ }^{1}$ Universidad de Los Andes. Cra 1 No. 18 $8^{\mathrm{a}}$-10, Bogotá, Colombia \\ ${ }^{2}$ Universidad San Francisco de Quito, Diego de Robles y Pampite, Quito, Ecuador \\ libagon@usfq.edu.ec; bcaicedo@uniandes.edu.co
}

\section{Extended Abstract}

Physical properties of the soil (i.e., color) do not allow any deformation measurement inside the model. For this reason, transparent synthetic soils are widely used for geotechnical 3D modeling since 2000 [1]. Transparency allows the study of soil behavior for several geotechnical structures, specifically the ones placed in the center of the model [2]. This research intends to develop a transparent synthetic soil model for deformation measurement purposes.

For this investigation, the physical and mechanical properties of the synthetic soil were evaluated. A mixture of crushed borosilicate glass and a glycerin solution composes the transparent material. In terms of physical properties, transparency, density, and particle size were analyzed. To reach the required transparency, the refractive index of the two constituent materials were matched [3]. The sought refractive index was achieved by adding distilled water into the glycerin, with $0.4 \%$ of water content for $99.6 \%$ of glycerin content proportions at a room temperature of $25^{\circ} \mathrm{C}$. Transparent synthetic soil has similar physical properties to natural sands. In detail, $20.2 \mathrm{kN} / \mathrm{m}^{3}$ of saturated unit weight $\left(\gamma_{\mathrm{sat}}\right), 12.5 \mathrm{kN} / \mathrm{m}^{3}$ of dry unit weight $\left(\gamma_{\mathrm{d}}\right), 62 \%$ of glycerin content $(\mathrm{w})$, void ratio $\mathrm{e}_{\min }=1.03$ and $\mathrm{e}_{\max }=1.25$ and a relative density of $75 \%$. Moreover, the particle size distribution of the granular material goes from $0.08 \mathrm{~mm}$ to $1 \mathrm{~mm}$. In effect, this size distribution classifies synthetic soil as sand. In terms of mechanical properties, transparent synthetic soil has also similar frictional characteristics to natural sands, $34.53^{\circ}$ of friction angle $(\varphi)$ and non-cohesive behavior.

The transparent synthetic material was used to study the soil behavior under the effect of a single driven pile. To achieve this, a complete transparent Plexiglas mold was built and the transparent soil was poured by phases. First, the liquid phase was poured into the mold. Second, a $1.5 \mathrm{~cm}$ layer of crushed material was poured into the liquid and air bubbles were taken out. Third, tracer particles were strategically seeded in a line located in the center of the model. After that, the process was repeated until a $7.5 \mathrm{~cm}$ height of transparent soil was completed. The constructed model was $14 \mathrm{~cm}$ wide (X-axis), $7.5 \mathrm{~cm}$ height (Y-axis) and $6 \mathrm{~cm}$ depth (Z-axis). At the end of the process, a $2 \mathrm{~cm}$ diameter pile was driven for $50 \mathrm{~mm}$ of penetration in the center of the model using a strain-controlled press. The pile driving velocity was $1 \mathrm{~mm} / \mathrm{min}$.

Seeded particles were tracked during the driven pile process and 3D soil deformation was analyzed. As a result, the driven pile process displaced soil particles along the three dimensions of the model. The particle displacement presents an upward parabolic movement. Under those circumstances, soil deformation was quantified in the X-axis and Y-axis plane using digital image correlation [4]. The maximum measured soil deformation was $3.5 \mathrm{~mm}$ in the $\mathrm{X}$-axis and $5 \mathrm{~mm}$ in the $\mathrm{Y}$ axis. To conclude, one plane along the $\mathrm{X}$-axis and $\mathrm{Y}$-axis of deformation was successfully measured in the center of the model. However, several deformation planes along the Z-axis can be measured using tracer particles in transparent soils.

\section{References}

[1] M. Iskander, R. J. Bathurst y M. Omidvar, "Past, Present, and Future of Transparent Soils," Geotechnical Testing Journal, pp. 557-573, 2015.

[2] F. M. Ezzein y R. J. Bathurst, “A transparent sand for geotechnical laboratory modeling,” Geotechnical Testing Journal, pp. 590-601, 2011.

[3] M. M. Cui y R. J. Adrian, "Refractive index matching and marking methods for highly concentrated solid - liquid flows," Experiments in fluids, pp. 261-264, 1977.

[4] L. Chen, M. Omidvar y M. Iskander, «Guidelines for DIC in geotechnical engineering research,» International Journal of Physical Modeling in Geotechniques, pp. 1-20, 2016. 